\title{
Erratum to: Influence of respiratory pressure support on hemodynamics and exercise tolerance in patients with COPD
}

\author{
Cristino Carneiro Oliveira $\cdot$ Cláudia Regina Carrascosa $\cdot$ Audrey Borghi-Silva \\ Danilo C. Berton · Fernando Queiroga Jr. • Eloara M. V. Ferreira • \\ Luiz E. Nery $\cdot$ J. Alberto Neder
}

Published online: 10 July 2010

(C) Springer-Verlag 2010

Erratum to: Eur J Appl Physiol (2010) 109:681-689

DOI 10.1007/s00421-010-1408-8

The name of Prof. J. Alberto Neder was erroneously captured as Alberto Neder, J. in the original publication of this article. The correct citation of his name should be Neder, J.A.

The online version of the original article can be found under doi:10.1007/s00421-010-1408-8.

C. C. Oliveira - C. R. Carrascosa · A. Borghi-Silva .

D. C. Berton · F. Queiroga Jr. · E. M. V. Ferreira .

L. E. Nery · J. A. Neder $(\bowtie)$

Pulmonary Function and Clinical Exercise Physiology

Unit (SEFICE), Division of Respiratory Diseases,

Department of Medicine, Paulista School of Medicine

(UNIFESP-EPM), Federal University of Sao Paulo,

Rua Professor Francisco de Castro 54 Vila Clementino,

São Paulo, SP CEP 04020-050, Brazil

e-mail: albneder@pneumo.epm.br

\section{A. Borghi-Silva}

Pulmonary Physiotherapy Laboratory,

Department of Physical Therapy, Federal University

of Sao Carlos (UFSCar), São Paulo, SP, Brazil 